\title{
Comparison of the umbilical cord Blood's anti-Mullerian hormone level in the newborns of mothers with polycystic ovary syndrome (PCOS) and healthy mothers
}

\author{
Faezeh Tadaion Far ${ }^{1}$, Shahideh Jahanian Sadatmahalleh', Saeideh Ziaei ${ }^{1 *}$ (i) and Anoshirvan Kazemnejad ${ }^{2}$
}

\begin{abstract}
Background: Polycystic ovary syndrome (PCOS) is one of the most common endocrine diseases. At present, the cause of the disease is not fully understood, but many studies have shown that PCOS is associated with genetic and environmental factors. The present study aimed to assess the umbilical cord blood's Anti-mullerian hormone $(\mathrm{AMH})$ level in the newborns of mothers suffering from PCOS comparing to healthy mothers.

Methods: This prospective cohort study was conducted on 120 pregnant women with PCOS, who were selected through Rotterdam criteria, and 60 healthy pregnant women as the control group. The subjects in each group were divided into obese and non-obese mothers according to their body mass index (BMI) before pregnancy. The cord blood samples were collected from the offsprings on the time of childbirth. Finally, the circulating concentrations of $\mathrm{AMH}$ in both sexes of the newborns were determined by specific assays.

Results: The research results showed that the blood level of AMH was higher in the neonates of obese mothers with PCOS comparing to the controls $(P<0.001)$. Mean AMH level was higher in male neonates born from nonobese PCOS mothers than in the controls $(P<0.001)$; however, there was not a significant difference in the level of $\mathrm{AMH}$ in female neonates between these two groups $(P=0.264)$. Also the level of the above biomarker was higher in both sexes of the neonates belonging to obese PCOS mothers compared with the neonates born from nonobese PCOS mothers $(P<0.001)$.

Conclusion(s): It can be said that the cord blood AMH level of neonates from obese women with PCOS is higher than that in the newborns of non-obese PCOS mothers. Further longitudinal studies are needed to confirm the clinical findings of the present research.
\end{abstract}

Keywords: Anti-Mullerian hormone (AMH), Polycystic ovary syndrome (PCOS), Ovarian function, Testicular function

\section{Background}

As the main cause of anovulatory infertility and hyperandrogenism, polycystic ovary syndrome (PCOS) is one of the most common (5-10\%) endocrine-metabolic dysfunctions in women. There is altered folliculogenesis observed in this syndrome, meaning an excessive number of growing follicles comparing to normal ovaries $[1,2]$. Anti-Mullerian hormone (AMH) is a dimeric

\footnotetext{
*Correspondence: Ziaei_sa@modares.ac.ir

${ }^{1}$ Department of Reproductive Health and Midwifery, Faculty of Medical

Sciences, Tarbiat Modares University, Tehran, Iran

Full list of author information is available at the end of the article
}

glycoprotein member of the transforming growth factor$\beta$ (TGF $\beta$ ) superfamily [3] that constitutes the marker of follicular development. It is exclusively produced in the gonads [4], whose dimorphic expression is critical in the testis and the ovary for the reproductive structures' normal differentiation $[5,6]$. During the early fetal development, the expression of Sertoli cells secreting AMH may end with Mullerian duct regression in men [4], whereas in the female fetus, the expression of granulosa cells secreting $\mathrm{AMH}$ takes place in the late gestation when the Mullerian ducts lose sensitivity to AMH [7]. Serum level of $\mathrm{AMH}$ seems to be associated with the development of

(c) The Author(s). 2019 Open Access This article is distributed under the terms of the Creative Commons Attribution 4.0 International License (http://creativecommons.org/licenses/by/4.0/), which permits unrestricted use, distribution, and reproduction in any medium, provided you give appropriate credit to the original author(s) and the source, provide a link to the Creative Commons license, and indicate if changes were made. The Creative Commons Public Domain Dedication waiver (http://creativecommons.org/publicdomain/zero/1.0/) applies to the data made available in this article, unless otherwise stated. 
preantral and small antral follicles, from puberty to the end of reproductive life [8]. During this period, the expression of $\mathrm{AMH}$ in the human ovary is much like to that in mice and rats [9], implying the crucial role of $\mathrm{AMH}$ in early follicle growth regulation. Research findings suggest that AMH level is $2-3$ times higher in PCOS women than in healthy women during the reproductive life $[1,10]$. Increase of the serum level of $\mathrm{AMH}$ in women with PCOS is associated with increase in the number of growing follicles secreting AMH [11]. Yet, it is to be known if AMH level increases before the clinical onset of PCOS, as defined by the Rotterdam ESHRE/ ASRM-sponsored PCOS consensus [12]. Phenotypic and family aggregation investigations on different populations have shown that hyperandrogenic symptoms and polycystic ovaries are more frequent in the first-degree relatives of PCOS patients than in healthy controls [1316]. The present study aimed to assess the umbilical cord blood's AMH level in the newborns of mothers suffering from PCOS comparing to healthy mothers.

\section{Methods}

This prospective cohort study was conducted aiming to assess the umbilical cord blood's AMH level in the newborns of mothers suffering from PCOS comparing to the controls in Tehran City/capital of Iran.

The sample size was calculated based on the previous study [ 17] [mean and standard deviation in each group of PCOS and non-PCOS]. By considering a significance level of $\alpha=0.05$, power of $1-\beta=0.80$, and maximum sample size for this study was calculated. The sample size was determined at least 60 participants for each group.

The research population included 180 mothernewborn pairs consisting of 120 neonates from PCOS mothers, and 60 neonates from healthy mothers referring to an obstetrics clinic (for prenatal care) and to Arash Comprehensive Maternity Hospital affiliated to Tehran Medical Science University (Tehran, Iran).

The inclusion criteria were: spontaneous singleton pregnancy, the age range of 18-40 years, having the least literacy of reading and writing, and Iranian nationality.

The National Institute of Health's (NIH) criteria (including chronic oligomenorrhea or amenorrhea and hirsutism or serum testosterone concentration of $>0.6 \mathrm{ng} /$ $\mathrm{ml}$ and/or free androgen index (FAI) of $>5.0$, and androstenedione concentration of $>3.0 \mathrm{ng} / \mathrm{ml}$ ) were the bases for PCOS diagnosis in the present study [18].

The exclusion criteria were: smokers, history of chemotherapy or radiotherapy history, late-onset 21hydroxylase deficiency, undergoing in vitro fertility, having hyperprolactinemia or androgen-secreting neoplasms, adult-onset congenital adrenal hyperplasia, the Cushing's syndrome, and thyroid disease.
Healthy women with regular menstrual cycles were selected as the controls. They had no history of any chronic medication use, hirsutism, hyperandrogenism, gestational diabetes, galactorrhea, thyroid dysfunction, and hypertension. The two groups (control and PCOS) were matched in the mother's age, education, employment, social-economical status, parity, and gestational age at labor, as well as the neonate's gender.

Neonates with genetic disorders, malformation or preterm delivery were excluded from the study.

After obtaining their written consent, the subjects in both groups were divided into obese and non-obese mothers according to their body mass index (BMI) before pregnancy. In each PCOS group, 31 male and 29 female infants were assessed. As the control group, we studied 34 male and 26 female infants born from healthy mothers. The newborns in both groups (control and PSCO) enjoyed normal birth weight.

This study was conducted with the approval of the Institutional Review Board (IRB), and of Tarbiat Modares University's Ethics Committee (IR.REC.1395.371). All the women were informed about the aims of the project and gave written consent before participating in the study.

\section{Laboratory measurements}

The umbilical cord blood samples were collected immediately post-delivery, centrifuged and then frozen at $45^{\circ} \mathrm{C}$. Serum AMH concentration of each umbilical cord blood sample was calculated using ELISA (Ct\# A79765 Immunotech-France) with 0.7 picomole sensitivity, having dispersion coefficients 12.3 and $14.2 \%$ in intratesting and inter-testing, respectively.

\section{Statistical analysis}

The SPSS software (ver. 18.0) (SPSS Inc., Chicago, IL., USA) was employed for data analysis. In order to check the quantitative data, the statistical KolmogorovSmirnov's test was applied $(P<0.05)$. Due to the abnormal distribution of the quantitative data of the research, Mann-Whitney's $\mathrm{U}$ and Kruskal-Wallis $\mathrm{H}$ tests were used to find out the relationship between the variables $(\mathrm{P}<0.05)$. Statistical significance was set at $P<0.05$.

\section{Results}

Totally, 180 pregnant women were assessed. In Table 1 , the frequency distribution, and the mean and standard deviation $(\mathrm{M} \pm \mathrm{SD})$ of the variables regarding the homogeneity of the groups are given. According to the study design, there was not a significant difference between the groups.

As shown in Table 2, the Kruskal-Wallis test revealed a significant statistical difference in terms of the mean AMH levels between the subdivisions of the cases, as 
Table 1 Frequency distribution, the mean and standard deviation of the variables in the study population

\begin{tabular}{|c|c|c|c|c|c|}
\hline \multicolumn{2}{|l|}{ Variables } & $\begin{array}{l}\text { Obese mothers with PCOS } \\
N=60\end{array}$ & $\begin{array}{l}\text { Non-obese mothers with PCOS } \\
N=60\end{array}$ & $\begin{array}{l}\text { Control } \\
N=60\end{array}$ & $P$-value \\
\hline \multicolumn{2}{|l|}{ Mother's age (months)* mean \pm SD } & $28.51 \pm 5.33$ & $26.56 \pm 4.39$ & $28.06 \pm 5.6$ & 0.076 \\
\hline \multicolumn{2}{|l|}{ Parity (mean $\pm \mathrm{SD})^{*}$} & $0.7 \pm 0.74$ & $0.53 \pm 0.72$ & $0.78 \pm 0.76$ & 0.117 \\
\hline \multicolumn{2}{|l|}{ Gestational age at labor (weeks) ${ }^{*}$ mean \pm SD } & $37.81 \pm 0.52$ & $37.78 \pm 0.52$ & $37.81 \pm 0.52$ & 0.944 \\
\hline \multirow[t]{3}{*}{ Economic status** (number/percent) } & Weak & $15(25)$ & 18(30) & 19(31.7) & \multirow[t]{3}{*}{0.054} \\
\hline & Normal & $27(45)$ & 28(46.7) & $36(60)$ & \\
\hline & Excellent & $18(30)$ & 14(23.3) & $5(8.3)$ & \\
\hline \multirow{2}{*}{$\begin{array}{l}\text { Neonate's gender** } \\
\text { (number/percent) }\end{array}$} & Male & $31(51.7)$ & $31(51.7)$ & $34(56.7)$ & \multirow[t]{2}{*}{0.818} \\
\hline & Female & 29(48.3) & 29(48.3) & $26(43.3)$ & \\
\hline \multirow[t]{2}{*}{ Employment status**(number/percent) } & Employee & 0 & 0 & $2(3.3)$ & \multirow[t]{2}{*}{0.132} \\
\hline & Housewife & $60(100)$ & $60(100)$ & $58(96.7)$ & \\
\hline \multirow{2}{*}{$\begin{array}{l}\text { Education** } \\
\text { (number/percent) }\end{array}$} & Diploma & $52(86.7)$ & $52(86.7)$ & $50(83.3)$ & \multirow[t]{2}{*}{0.712} \\
\hline & Academic & $8(13.3)$ & $8(13.3)$ & $10(16.7)$ & \\
\hline
\end{tabular}

*Based on Kruskal-Wallis $\mathrm{H}$ test results **Based on Chi-square test results

well as between the cases and the control group $(P<$ $0.001)$.

The results indicated that the mean AMH levels in the cord blood of newborns in both sexes were statistically higher in the obese mothers suffering from PCOS (male: $27.07 \pm 3.26$ vs. female: $0.94 \pm 0.31$ ) as compared to the controls (male: $23.30 \pm 0.63$ vs. female: $0.25 \pm 0.11, P<$ 0.001). Mean serum level of AMH in the cord blood of the male neonates of non-obese PCOS mothers was statistically higher than in the controls $(24.86 \pm 1.89$ vs. $23.15 \pm 1.74, P<0.001$ ). However, the comparison was not statistically significant in case of the female newborns $(0.34 \pm 0.23$ vs. $0.23 \pm 0.12, P=0.264)$. Also the mean AMH levels in the cord blood of newborns in both genders born from obese mothers with PCOS (male: $27.07 \pm 3.26$ vs. female: $0.94 \pm 0.31)$ compared with the non-obese PCOS mothers (male: $24.86 \pm 1.89$ vs. $0.34 \pm$

Table 2 Anti-Mullerian hormone concentration in the cord blood of newborns in the study population

\begin{tabular}{|c|c|c|c|c|}
\hline $\mathrm{AMH}(\mathrm{ng} / \mathrm{ml})$ & & & & \\
\hline $\begin{array}{l}\text { Gender } \\
\text { Group }\end{array}$ & Male & $95 \% \mathrm{Cl}$ & Female & $95 \% \mathrm{Cl}$ \\
\hline $\begin{array}{l}\text { Obese cases having PCOS } \\
N=60\end{array}$ & $\begin{array}{l}27.07 \pm \\
3.26\end{array}$ & $\begin{array}{l}(25.87- \\
28.26)\end{array}$ & $\begin{array}{l}0.94 \pm \\
0.31\end{array}$ & $\begin{array}{l}(0.82- \\
1.06)\end{array}$ \\
\hline $\begin{array}{l}\text { Non-obese cases having } \\
\text { PCOS } \\
N=60\end{array}$ & $\begin{array}{l}24.86 \pm \\
1.89\end{array}$ & $\begin{array}{l}(24.16- \\
25.55)\end{array}$ & $\begin{array}{l}0.34 \pm \\
0.23\end{array}$ & $\begin{array}{l}(0.25- \\
0.43)\end{array}$ \\
\hline $\begin{array}{l}\text { Non-obese control } \\
N=30\end{array}$ & $\begin{array}{l}23.15 \pm \\
1.74\end{array}$ & $\begin{array}{l}(22.25- \\
24.04)\end{array}$ & $\begin{array}{l}0.23 \pm \\
0.12\end{array}$ & $\begin{array}{l}(0.16- \\
0.31)\end{array}$ \\
\hline $\begin{array}{l}\text { Obese control } \\
\mathrm{N}=30\end{array}$ & $\begin{array}{l}23.30 \pm \\
0.63\end{array}$ & $\begin{array}{l}(22.97- \\
23.63)\end{array}$ & $\begin{array}{l}0.25 \pm \\
0.11\end{array}$ & $\begin{array}{l}(0.18- \\
0.32)\end{array}$ \\
\hline P-value & $<0.001$ & & $<0.001$ & \\
\hline
\end{tabular}

Values are Mean \pm SD (based on Kruskal-Wallis $\mathrm{H}$ test results) AMH: Anti-Mullerian Hormone

$\mathrm{Cl}$ : Confidence Intervals
$0.23)$ were significantly higher $(P<0.001)$, but there was no significant difference between the mean level of $\mathrm{AMH}$ in the cord blood of male $(23.30 \pm 0.63)$ and female $(0.25 \pm 0.11)$ infants from obese control mothers with male $(23.15 \pm 1.74)$ and female $(0.23 \pm 0.12)$ infants from non-obese control mothers $(P=0.522, P=0.871)$ (data not shown).

\section{Discussion}

The current study aimed at assessing the umbilical cord blood's AMH level in the newborns of PCOS mothers comparing to healthy control mothers.

It was found that the mean serum AMH concentration of the umbilical cord blood of the neonates born from obese/non-obese PCOS mothers was higher as compared to the controls $(P<0.001)$. However, regarding the female neonates, in spite of the considerable difference between the serum AMH level in the two groups (nonobese mothers with $\mathrm{PCOS} /$ controls), no significant statistical difference was observed between them $(P=0.264)$. Also the mean level of AMH was higher in the cord blood of neonates of obese mothers with PCOS comparing to the non-obese PCOS women $(P<0.001)$.

In the following, some of the studies done on PCOS are presented:

In 2006, Teresa-Sir Petermann et al. compared 2-3 months old and 4-7 years old prepubertal girl infants of mothers with PCOS and those born from healthy mothers (control group). The results showed that the serum level of AMH in the PCOS group was significantly higher than in the control group during the infancy and childhood [19].

Nicolas Crisosto et al. (2007) compared the daughters (8-16 yr old) born from PCOS and healthy women. The 
results indicated that the PCOS group had significantly higher AMH level than their control counterparts [20].

In 2008, Sergio E. Recabarren et al. [21] compared the males (infants, children, and adults) born from PCOS and healthy mothers. It was revealed that the PCOS group had higher AMH level than the controls during both infancy and childhood.

In 2011, Nicolas Crisosto et al. found that AMH serum level in the female neonates born from mothers with PCOS, who had not been treated with metformin during pregnancy, was higher compared to the control group; however, its level in the female neonates born from mothers having PCOS, who had been treated with metformin during pregnancy, was similar to that in the control group [17].

In 2012, Teresa -Sir Petermann et al. reported that the AMH serum level and the ovarian volume in the case group were more than those in the control group during all Tanner stages [22]. But we evaluated the serum concentrations of AMH in the cord blood of both sexes of newborns from PCOS and healthy mothers.

The above studies confirm our findings. Though we assessed the umbilical cord blood's AMH level in the newborns of PCOS mothers to the controls. It was found that $\mathrm{AMH}$ concentration of the umbilical cord blood of the neonates from obese/ nonobese PCOS mothers was higher as compared to the the controls. This phenomenon can be justified with regard to environmental or genetic factors. PCOS has a genetic etiology [23], as well as many candidate genes [24]. In addition, the endocrine, nutritional, and metabolic milieu of the fetus may have a programming effect, which may persist in adult life [25-27]. Further more, PCOS women show a considerable increase in androgen level during pregnancy, as a potential androgen source to the fetus [28]. Hence, possibly, high levels of androgen observed in pregnant women suffering from PCOS may affect the fetal physiology and thus lead to the ovarian morphology and function changes as described in the experimental models. Research findings on rhesus monkeys imply that intraovarian androgens inhibit apoptosis and promote granulosa cell proliferation, especially in small follicles having granulosa cells rich in androgen receptors [29]. In a recent experimental study, male sheep born to testosterone-exposed mothers exhibited an increased FSH receptor expression in the testis [21]. Under the condition of androgenic inhibition, FSH increases the serum level of AMH through promoting the proliferation of Sertoli cells [30]. Thus, it can be said that the serum level of AMH increases in the offspring of PCOS women can be indicative of an increase in the ovarian follicular reserve quantity or hyperactivity of Sertoli cells. Besides, contrary to other studies, the current study findings do not confirm a significant relationship in the cord blood AMH levels of female neonates from nonobese mothers suffering from PCOS and the controls. This can be due to more sample size of the above studies.

Also, based on the results of some previous studies [31-34], the strong independent positive effect of Luteinizing Hormone (LH) on the granulosa cell production of AMH has been demonstrated in the consistently higher $\mathrm{AMH}$ levels in normal-weight women, comparing to obese and overweight women. Although in a previous report on adolescent PCOS girls [34], no significant association was observed between AMH levels and BMI. In two other studies [35, 36], AMH levels were lower by $65 \%$ in the obese women than in the normalweight women of late reproductive age. Therefore, the serum level of AMH has a reverse relationship with BMI in individuals suffering from PCOS. But the present study indicated opposite results to previous suggestions in this rgard. This is justifiable under the hypothesis that often the women with PCOS have circumstantial resistance to insulin, which plays a key role in the pathogenesis of the syndrome. Eventually, hyperinsulinemia is linked to hyperandrogenism, since insulin acts in the theca cells, potentiating the effects of LH on steroidogenesis. Insulin also has a stimulating effect on steroidogenesis in the granulosa cells, increasing androgen levels and resulting in a greater number of follicles in growth starting from the follicle recruitment phase, suggesting a correlation with increased AMH production [37]. A recent study on the effects of Myo-inositol on serum $\mathrm{AMH}$ in patients with PCOS showed a significant improvement in $\mathrm{AMH}$, fasting glucose, ovarian volume, ovarian antral follicle, and total antral follicle count [38]. It may improve clinical and hormonal features of PCOS patients by enhancing insulin sensitivity that decreases [39]. There is evidence that the occurrence of insulin resistance in non-pregnant women suffering from PCOS varies between 50 and $80 \%$ [37]. In addition, obesity, through reducing insulin sensitivity and increasing the availability of glucose for maternal-fetal transport [40], promotes intrauterine growth [41]. Moreover, it has been demonstrated that obese women exhibit higher glucose levels during pregnancy than normal-weight women. Even if these glucose levels do not reach the range for gestational diabetes, the impact on the fetal pancreas is similar to that of gestational diabetes [42] so that it causes fetal hyperinsulinemia. Besides, insulin as a trophic factor for granulosa and Sertoli cells- may increase the number of AMH producing cells although we cannot exclude the possibility that each granulosa and Sertoli cell could produce more AMH in response to insulin. Conversely, a higher number of follicles reflected by high AMH levels could determine higher androgen levels related to hyperinsulinemia [43]. AMH 
is found may increase to three to four-fold in PCOS patients as evidenced by previous studies. Elevated AMH concentration in PCOS patients is largely due to increased production by individual follicles rather than increased follicle number [44], which may confound its association with ovarian reserve and/or quality, thus explaining the poor predictability of AMH. Furthermore, available data suggest the role of AMH in inhibiting folliculogenesis by interference with the concentration and the actions of FSH in the ovaries [45]. some previous studies $[46,47]$ reported a reduced ovarian response in PCOS women when AMH level is above a threshold value $(4.7 \mathrm{ng} / \mathrm{ml})$. Therefore, PCOS patients require dose step up during ART cycles, and are at higher risk for severe OHSS.

The present research, had some limitations. First, the sample size is small and the findings are inconsistent with the results of some other works, may be due to this reason. Second, we did not divide the patients with PCOS into four groups based on Rotterdam criteria. Piouka et al. [36] reported the different levels of AMH in four groups.

The strength of the current study was that the differences observed could not be explained by some confounding factors because some parameters were matched as far as possible between the four groups. Also the increased levels of AMH in umbilical cord blood could reflect the endocrinal effect of mother's hormone on the earlier developement of the fetus.

\section{Conclusions}

It is concluded that the cord blood AMH level of neonates from obese women with PCOS is higher than in the newborns of non-obese PCOS mothers. In order to reach a conclusion with more certainty, it is recommended to do a comparative study with large scope of PCOS mothers with male and female newborns.

\section{Abbreviations \\ AMH: Anti-Mullerian Hormone; BMl: Body Mass Index; FAl: Free Androgen Index; IRB: Institutional Review Board; LH: Luteinizing Hormone; NIH: National Institute of Health; PCOS: Polycystic Ovary Syndrome; TGF $\beta$ : Transforming Growth Factor- $\beta$}

\section{Acknowledgments}

The authors wish gratefully acknowledges the contribution of the participating women. There is no conflict of interest. This study was funded by Tarbiat Modares University.

\section{Availability of data and material}

The datasets used and/or analyzed during the current study are available from the corresponding author on reasonable request.

\section{Authors' contributions}

SZ, ShJS study concept and design; FT acquisition of data; AK, SZ, ShJS analysis and interpretation of data; SZ, ShJS drafting of the manuscript; SZ,FT critical revision of the manuscript for important intellectual content; AK, SZ, FT statistical analysis; SZ, ShJS administrative, technical, and material support. All authors read and approved the final manuscript.
Funding

The authors declare that they have no funding.

\section{Ethics approval and consent to participate}

This study was conducted with the approval of the Institutional Review Board (IRB), and of Tarbiat Modares University's Ethics Committee (IR.REC.1395.371).

\section{Consent for publication}

All the women were informed about the aims of the project and gave written consent before participating in the study.

\section{Competing interests}

The authors declare that they have no competing interests.

\section{Author details}

'Department of Reproductive Health and Midwifery, Faculty of Medical Sciences, Tarbiat Modares University, Tehran, Iran. ${ }^{2}$ Department of Biostatistics, Faculty of Medical Sciences, Tarbiat Modares University, Tehran, Iran.

Received: 22 June 2019 Accepted: 17 October 2019

Published online: 17 November 2019

\section{References}

1. Pigny P, Merlen E, Robert $Y$, et al. Elevated serum level of anti-mullerian hormone in patients with polycystic ovary syndrome: relationship to the ovarian follicle excess and to the follicular arrest. J Clin Endocrinol Metab. 2003:88:5957-62.

2. Webber L, Stubbs S, Stark J, et al. Formation and early development of follicles in the polycystic ovary. Lancet. 2003;362:1017-21.

3. Josso N, di Clemente N. TGF- $\beta$ family members and gonadal development. Trends Endocrinol Metab. 1999;10:216-22

4. Lee MM, Donahoe PK. Mullerian inhibiting substance: a gonadal hormone with multiple functions. Endocr Rev. 1993;14:152-64.

5. Josso N, Cate RL, Picard J-Y, et al. Anti-Müllerian hormone: the Jost factor. Recent Prog Horm Res; 1993. p. 1-59.

6. Josso N, Lamarre I, Picard J-Y, et al. Anti-Müllerian hormone in early human development. Early Hum Dev. 1993;33:91-9.

7. Rajpert-De Meyts E, Jørgensen N, Græm N, et al. Expression of anti-Mullerian hormone during normal and pathological gonadal development: association with differentiation of Sertoli and granulosa cells. J Clin Endocrinol Metab. 1999:84:3836-44.

8. Cook CL, Siow Y, Taylor S, Fallat ME. Serum müllerian-inhibiting substance levels during normal menstrual cycles. Fertil Steril. 2000;73:859-61.

9. Weenen C, Laven JS, von Bergh AR, et al. Anti-Müllerian hormone expression pattern in the human ovary: potential implications for initial and cyclic follicle recruitment. Mol Hum Reprod. 2004;10:77-83.

10. Laven JS, Mulders AG, Visser JA, et al. Anti-Mullerian hormone serum concentrations in normoovulatory and anovulatory women of reproductive age. J Clin Endocrinol Metab. 2004;89:318-23.

11. Piltonen $T$, Morin-Papunen $L$, Koivunen $R$, et al. Serum anti-Müllerian hormone levels remain high until late reproductive age and decrease during metformin therapy in women with polycystic ovary syndrome. Hum Reprod. 2005;20:1820-6.

12. Caruso-Nicoletti M, editor Sindrome dell'ovaio policistico: novità nella diagnosi e nel trattamento. XII Congresso Nazionale Società Italiana di Medicina dell'Adolescenza; 2003.

13. Cooper HE, Spellacy W, Prem K, Cohen W. Hereditary factors in the steinLeventhal syndrome. Am J Obstet Gynecol. 1968;100:371-87.

14. HAGUE WM, ADAMS J, REEDERS ST, PETO TE, JACOBS HS. Familial polycystic ovaries: a genetic disease? Clin Endocrinol. 1988;29:593-605.

15. Wallach EE, Goldzieher JW. Polycystic ovarian disease. Fertil Steril. 1981;35: 371-94.

16. Lunde $O$, Magnus P, Sandvik L, Høglo S. Familial clustering in the polycystic ovarian syndrome. Gynecol Obstet Investig. 1989;28:23-30.

17. Crisosto N, Echiburú B, Maliqueo M, et al. Improvement of hyperandrogenism and hyperinsulinemia during pregnancy in women with polycystic ovary syndrome: possible effect in the ovarian follicular mass of their daughters. Fertil Steril. 2012;97:218-24. 
18. Artini PG, Di Berardino $O$, Simi G, et al. Best methods for identification and treatment of PCOS. Minerva Ginecol. 2010;62:33.

19. Sir-Petermann $T$, Codner $E$, Maliqueo $M$, et al. Increased anti-Mullerian hormone serum concentrations in prepubertal daughters of women with polycystic ovary syndrome. J Clin Endocrinol Metab. 2006;91:3105-9.

20. Ns C, Codner E, Maliqueo M, et al. Anti-Mullerian hormone levels in peripubertal daughters of women with polycystic ovary syndrome. J Clin Endocrinol Metab. 2007;92:2739-43.

21. Recabarren SE, Sir-Petermann T, Rios R, et al. Pituitary and testicular function in sons of women with polycystic ovary syndrome from infancy to adulthood. J Clin Endocrinol Metab. 2008;93:3318-24.

22. Sir-Petermann T, ALd G, Codner E, et al. Relationship between anti-Müllerian hormone $(\mathrm{AMH})$ and insulin levels during different tanner stages in daughters of women with polycystic ovary syndrome. Reprod Sci. 2012;19: 383-90.

23. Franks S, Gharani N, Waterworth D, et al. The genetic basis of polycystic ovary syndrome. Human reproduction (Oxford, England). 1997:12:2641-8.

24. Urbanek M, Legro RS, Driscoll DA, et al. Thirty-seven candidate genes for polycystic ovary syndrome: strongest evidence for linkage is with follistatin. Proc Natl Acad Sci. 1999;96:8573-8.

25. Barker DJP. Mothers, babies and disease in later life: BMJ publishing group; 1994.

26. Holemans K, Aerts L, Van Assche FA. Fetal growth and long-term consequences in animal models of growth retardation. Eur J Obstet Gynecol Reprod Biol. 1998:81:149-56.

27. Rhind SM, Rae MT, Brooks AN. Effects of nutrition and environmental factors on the fetal programming of the reproductive axis. Reproduction. 2001;122: 205-14.

28. Sir-Petermann T, Maliqueo M, Angel B, et al. Maternal serum androgens in pregnant women with polycystic ovarian syndrome: possible implications in prenatal androgenization. Hum Reprod. 2002;17:2573-9.

29. Vendola KA, Zhou J, Adesanya OO, Weil SJ, Bondy CA. Androgens stimulate early stages of follicular growth in the primate ovary. J Clin Invest. 1998;101: 2622-9.

30. Al-Attar L, Noël K, Dutertre M, et al. Hormonal and cellular regulation of Sertoli cell anti-Müllerian hormone production in the postnatal mouse. J Clin Invest. 1997;100:1335-43.

31. Løbo RA, Kletzky OA, Campeau JD. Elevated bioactive luteinizing hormone in women with the polycystic ovary syndrome. Fertil Steril. 1983;39:674-8.

32. Panidis D, Farmakiotis D, Rousso D, et al. Plasma visfatin levels in normal weight women with polycystic ovary syndrome. Eur J Intern Med. 2008;19: 406-12.

33. Panidis D, Koliakos $G$, Kourtis A, et al. Serum resistin levels in women with polycystic ovary syndrome. Fertil Steril. 2004:81:361-6.

34. Siow $Y$, Kives $S$, Hertweck $P$, Perlman $S$, Fallat ME. Serum Müllerian-inhibiting substance levels in adolescent girls with normal menstrual cycles or with polycystic ovary syndrome. Fertil Steril. 2005;84:938-44.

35. Freeman EW, Gracia CR, Sammel MD, et al. Association of anti-mullerian hormone levels with obesity in late reproductive-age women. Fertil Steril. 2007:87:101-6.

36. Piouka A, Farmakiotis D, Katsikis I, et al. Anti-Mullerian hormone levels reflect severity of PCOS but are negatively influenced by obesity: relationship with increased luteinizing hormone levels. Am J Physiol Endocrinol Metab. 2009; 296:E238-43.

37. H-x XIA, ZHANG W. Study of association between polycystic ovary syndrome and dietary intake. J Reprod Contracept. 2012;23:29-40.

38. Ozay AC, Emekci Ozay O, Okyay RE, et al. Different effects of Myoinositol plus folic acid versus combined Oral treatment on androgen levels in PCOS women. Int J Endocrinol. 2016:2016:3206872.

39. Lagana AS, Rossetti P, Sapia F, et al. Evidence-based and patient-oriented inositol treatment in polycystic ovary syndrome: changing the perspective of the disease. Int J Endocrinol Metab. 2017;15:e43695.

40. Di GC, Benzi L, Bottone P, et al. Neonatal outcome and obstetric complications in women with gestational diabetes: effects of maternal body mass index. Int J Obes Relat Metab Disord. 1996;20:445-9.

41. Stevenson DK, Hopper AO, Cohen RS, et al. Macrosomia: causes and consequences. J Pediatr. 1982;100:515-20.

42. Ramsay JE, Ferrell WR, Crawford L, et al. Maternal obesity is associated with dysregulation of metabolic, vascular, and inflammatory pathways. J Clin Endocrinol Metab. 2002:87:4231-7.
43. Golden SH, Ding J, Szklo M, et al. Glucose and insulin components of the metabolic syndrome are associated with hyperandrogenism in postmenopausal women: the atherosclerosis risk in communities study. Am J Epidemiol. 2004;160:540-8.

44. Pellatt L, Hanna L, Brincat M, et al. Granulosa cell production of antiMullerian hormone is increased in polycystic ovaries. J Clin Endocrinol Metab. 2007:92:240-5.

45. Garg D, Tal R. The role of AMH in the pathophysiology of polycystic ovarian syndrome. Reprod BioMed Online. 2016;33:15-28.

46. Gulsen MS, Ulu I, Yildirim Kopuk S, Kiran G. The role of anti-Mullerian hormone in predicting clomiphene citrate resistance in women with polycystic ovarian syndrome. Gynecol Endocrinol. 2019;35:86-9.

47. Di Paola R, Garzon S. Are we choosing the correct FSH starting dose during controlled ovarian stimulation for intrauterine insemination cycles? Arch Gynecol Obstet. 2018;298:1029-35.

\section{Publisher's Note}

Springer Nature remains neutral with regard to jurisdictional claims in published maps and institutional affiliations.

Ready to submit your research? Choose BMC and benefit from:

- fast, convenient online submission

- thorough peer review by experienced researchers in your field

- rapid publication on acceptance

- support for research data, including large and complex data types

- gold Open Access which fosters wider collaboration and increased citations

- maximum visibility for your research: over $100 \mathrm{M}$ website views per year

At $\mathrm{BMC}$, research is always in progress.

Learn more biomedcentral.com/submissions 